Preface

\title{
An Update on the Thrombotic Microangiopathies Hemolytic Uremic Syndrome (HUS) and Thrombotic Thrombocytopenic Purpura (TTP)
}

\author{
Magdalena Riedl, MD ${ }^{1,2,3}$ Dorothea Orth-Höller, MD \\ ${ }^{1}$ Department of Pediatrics I, Innsbruck Medical University, \\ Innsbruck, Austria \\ 2 Division of Nephrology, The Hospital for Sick Children, Toronto, \\ Ontario, Canada \\ ${ }^{3}$ Research Institute, Cell Biology Program, The Hospital for Sick \\ Children, Toronto, Ontario, Canada \\ ${ }^{4}$ Division of Hygiene \& Medical Microbiology, Innsbruck Medical \\ University, Innsbruck, Austria
}

Semin Thromb Hemost 2014;40:413-415.

Welcome to this special issue of Seminars in Thrombosis $\mathcal{E}$ Hemostasis, which summarizes up-to-date knowledge on pathogenesis, diagnosis, and treatment of thrombotic microangiopathies (TMAs) such as (enterohemorrhagic) E. coli (EHEC)-associated hemolytic uremic syndrome (HUS) (eHUS), atypical HUS (aHUS), (aHUS) and thrombotic thrombocytopenic purpura (TTP). This issue also reviews C3 glomerulopathies (C3G), emphasizing the expanding spectrum of TMAs.

The introduction to this issue is provided by Sethi and Fervenza who revise, from a morphological and histological view, the current classification of C3G based on renal pathology and explaining the typical features of the different complement-mediated diseases on biopsy. They introduce the role of uncontrolled complement activation of the alternative pathway in the pathogenesis of $\mathrm{C} 3 \mathrm{G}$, using new methods such as mass spectrometry of microdissected glomeruli. ${ }^{1}$

de Cordoba et al then review up-to-date knowledge on the inherited form of aHUS and thus on genetics, including recent findings such as complement factor $\mathrm{H}$ (CFH) and/or factor $\mathrm{H}-$ related (CFHR) genomic rearrangements and mutations in the coagulation cascade. It is commonly understood that multiple hits, involving genetic/autoimmune defects of complement regulators and proteins, are likely required to impair protection of endothelial cells. The genetic susceptibility is increased if an individual carries a combination of inherited defects. ${ }^{2}$

For the acquired form of aHUS, Hofer et al describe in their review on CFH antibody-associated HUS (CFH-Ab HUS) the current knowledge on $\mathrm{CFH}-\mathrm{Ab}$ detection, the association with CFHR3-CFHR1 deletion, and the different treatment options.
The significance of a rapid CFH-Ab HUS diagnosis is crucial, as the treatment algorithm differs from other aHUS patients. ${ }^{3}$

Insights into endothelial cell activation and inflammation involved in TMA pathogenesis are reviewed in detail by Riedl et al. Increasing knowledge on aHUS and an expanding TMA spectrum have evolved over the last years ( - Table 1). Complement emerges as a crucial regulator, as it plays a central role in maintaining this homeostasis within the microvasculature. Defects in the complement system, raising the individual susceptibility to TMA evolvement, were discovered in affected patients. The successful use of eculizumab in patients with aHUS or the extended TMA spectrum corroborates the role of complement in TMA pathogenesis. ${ }^{4}$

Xiao et al focus on the functional aspects of the complement system and, in particular, on the genetic complement disorders in C3G patients, such as CFH-related protein dimerization and complex formation. Abnormal CFHR proteins detected in patients with C3G may promote formation of unusual dimers and/or multimers impacting complement control. ${ }^{5}$

Eculizumab, a monoclonal antibody binding $\mathrm{C} 5$, has been used in 11 C3G patients so far, as reported by Vivarelli and Emma. A significant response was seen in eight patients with evidence for terminal complement activation. As patients with C3G show a great deal of interindividual variety, a patient-tailored complement-targeting treatment might be the ideal approach in the future. ${ }^{6}$

Safouh and coworkers (Hofer et al) share the experience of a pediatric nephrologist in Cairo, Egypt, in the review on HUS in the developing world. This is an important contribution, as patients outnumber every cohort in the developed world and
Address for correspondence Reinhard Würzner, MD, PhD, Division of Hygiene and Medical Microbiology, Innsbruck Medical University, Schöpfstr. 41, A-6020 Innsbruck, Austria (e-mail: Reinhard.Wuerzner@i-med. ac.at).
Issue Theme An Update on the Thrombotic Microangiopathies Hemolytic Uremic Syndrome (HUS) and Thrombotic Thrombocytopenic Purpura (TTP); Guest Editors, Magdalena Riedl, MD, Dorothea Orth-Höller, MD, and Reinhard Würzner, MD, PhD.
Copyright $\odot 2014$ by Thieme Medical Publishers, Inc., 333 Seventh Avenue, New York, NY 10001, USA. Tel: +1(212) 584-4662.
DOI http://dx.doi.org/ 10.1055/s-0034-1376521. ISSN 0094-6176. 
Table 1 Classification of thrombotic microangiopathies

\begin{tabular}{|c|}
\hline $\begin{array}{l}\text { Infection induced TMA } \\
\text { - (Enterohemorrhagic) E. coli-associated HUS } \\
\text { - Shigella dysenteriae-associated HUS } \\
\text { - Streptococcus pneumonia-associated HUS } \\
\text { - Influenza A/H1N1-associated HUS } \\
\text { - HUS due to other pathogens: EBV, CMV, Mycoplasma pneumoniae, Bordetella pertussis, Parvovirus B19, HIV }\end{array}$ \\
\hline $\begin{array}{l}\text { TMA associated with disorders of complement regulation-atypical HUS } \\
\text { - Hereditary } \\
\text { - Autoimmune }\end{array}$ \\
\hline TMA manifesting during pregnancy or postpartum \\
\hline $\begin{array}{l}\text { TMA associated with transplantation } \\
\text { - TMA developed de novo after solid organ transplantation } \\
\text { - TMA associated with bone-marrow or stem-cell transplantation }\end{array}$ \\
\hline $\begin{array}{l}\text { TMA associated with metabolic diseases } \\
\text { - Cobalamin C deficiency }\end{array}$ \\
\hline $\begin{array}{l}\text { TMA associated with other glomerulopathies/vasculitides } \\
\text { - Systemic lupus erythematosus/antiphospholipid syndrome } \\
\text { - C3 glomerulopathy } \\
\text { - Others: Immunoglobulin A nephropathy, focal segmental glomerulosclerosis, vasculitis }\end{array}$ \\
\hline TMA associated with malignant hypertension \\
\hline $\begin{array}{l}\text { Drug induced TMA } \\
\text { - Calcineurin inhibitors } \\
\text { - Others: quinine, ticlopidine, chemotherapy }\end{array}$ \\
\hline $\begin{array}{l}\text { Other forms of TMA } \\
\text { - DGKE mutation } \\
\text { - Unknown }\end{array}$ \\
\hline $\begin{array}{l}\text { TMA associated with ADAMTS13 deficiency-thrombotic thrombocytopenic purpura } \\
\text { - Hereditary } \\
\text { - Autoimmune }\end{array}$ \\
\hline
\end{tabular}

Abbreviations: DGKE, diacylglycerol kinase epsilon; HUS, hemolytic uremic syndrome; TMA, thrombotic microangiopathy.

diagnostic and therapeutic tools differ substantially. They introduce an overview on available complement diagnostics, as well as recommendations on diagnosis and treatment tailored for developing countries. Recommendations include a two-step approach, starting with available resources locally and subsequent support of developed world for in-depth analysis. ${ }^{7}$

The most prominent inherited form of TTP in children, the Upshaw-Schulman syndrome (USS), is caused by homozygous or compound heterozygous mutations in the ADAMTS13 gene. Hassenpflug et al review current experience to highlight that the rare and oligosymptomatic symptoms might obscure the diagnosis and that the pentad attributed to this disease is much less frequent than commonly believed. Detailed analyses of 30 USS patients revealed mutations distributed over the whole ADAMTS13 gene, without any genotype-phenotype correlation. ${ }^{8}$

Considerable progress has been made in diagnosis and therapy of TTP. In acquired forms of TTP plasma exchange, immunosuppression and rituximab have improved outcome as reviewed by Knöbl. New approaches including recombinant ADAMTS13, N-acetylcysteine, and anti-von Willebrand factor A1 agents reflect promising treatments for the future. ${ }^{9}$
The role of complement in EHEC-associated HUS is reviewed by Orth-Höller and Würzner. Complement activation had been observed in vivo in HUS patients. In vitro experiments have then demonstrated that Shiga toxin 2 directly activates complement and interacts with soluble complement regulators, namely, CFH, CFHR-1, and factor $\mathrm{H}-$ like protein 1, leading to an impaired complement control. Furthermore, Shiga toxin 2 also modulates membrane-bound regulators by downregulating expression of CD59. These findings served as a rationale for using eculizumab in patients with EHEC-associated HUS, especially during the 0104:H4 outbreak in Germany in 2011. ${ }^{10}$

Finally, Würzner et al ${ }^{11}$ detail that in EHEC-associated HUS (or eHUS), antibiotic treatment should still be avoided during the gastrointestinal phase. Complement inhibition, however, may make the difference between favorable or detrimental outcome in severe cases. Experiences on the use of eculizumab are discussed, recognizing that only a randomized trial can answer the question of optimal treatment time, treatment duration, and patient population which will benefit from treatment. ${ }^{11}$ 


\section{References}

1 Sethi S, Fervenza FC. Pathology of renal diseases associated with dysfunction of the alternative pathway of complement: C3 glomerulopathy and atypical hemolytic uremic syndrome (aHUS). Semin Thromb Hemost 2014;40(4):416-421

2 de Cordoba SR, Hidalgo MS, Pinto S, Tortajada A. Genetics of atypical hemolytic uremic syndrome (aHUS). Semin Thromb Hemost 2014;40(4):422-430

3 Hofer J, Giner T, Jözsi M. Complement factor H-antibody-associated hemolytic uremic syndrome: pathogenesis, clinical presentation and treatment. Semin Thromb Hemost 2014;40(4):431-443

4 Riedl M, Fakhouri F, Le Quintrec M, et al. Spectrum of complementmediated thrombotic microangiopathies: pathogenetic insights identifying novel treatment approaches. Semin Thromb Hemost 2014;40(4):444-464

5 Xiao X, Pickering MC, Smith RJ. C3 glomerulopathy: the genetic and clinical findings in dense deposit disease and $\mathrm{C} 3$ glomerulonephritis. Semin Thromb Hemost 2014;40(4):465-471
6 Vivarelli M, Emma F. Treatment of C3 glomerulopathy with complement blockers. Semin Thromb Hemost 2014;40(4): 472-477

7 Hofer J, Giner T, Safouh H. Diagnosis and treatment of the hemolytic uremic syndrome disease spectrum in developing regions. Semin Thromb Hemost 2014;40(4):478-486

8 Hassenpflug WA, Budde U, Schneppenheim S, Schneppenheim R. Inherited thrombotic thrombocytopenic purpura in children. Semin Thromb Hemostat 2014;40(4):487-492

9 Knöbl P. Inherited and acquired thrombotic thrombocytopenic purpura (TTP) in adults. Semin Thromb Hemost 2014;40(4): 493-502

10 Orth-Höller D, Würzner R. Role of complement in enterohemorrhagic Escherichia coli-induced hemolytic uremic syndrome. Semin Thromb Hemost 2014;40(4):503-507

11 Würzner R, Riedl M, Rosales A, Orth-Höller D. Treatment of enterohemorrhagic Escherichia coli-induced hemolytic uremic syndrome (eHUS). Semin Thromb Hemost 2014;40(4):508-516 